\title{
PERANCANGAN E-COMMERCE PADA PT DAF
}

\author{
Rudy $^{1}$; George A. A. ${ }^{2}$; Ryan M. A. ${ }^{3}$; Yohanna ${ }^{4}$ \\ Jurusan Sistem Informasi, Fakultas Ilmu Komputer, Universitas Bina Nusantara \\ Jln. K.H. Syahdan No. 9, Palmerah, Jakarta Barat 11480 \\ Rudy@binus.edu
}

\begin{abstract}
The purpose of this study is to analyze and design e-commerce at. DAF to help the sales process is then expected to improve service. The methodology used is the method of analysis, where the review is held directly to the field, observing and analyzing the data obtained, and using the design method, which includes design of business models, screen designs and database design. Results to be achieved is the application of e-commerce web-based, whereby the system can enable customers to obtain the desired information is complete, make transactions easier and faster. Conclusions obtained are PT DAF can take advantage of e-commerce to support their business today and an appropriate business model is the highest-quality models.
\end{abstract}

Keywords: web, e-commerce, sales, applications, business

\begin{abstract}
ABSTRAK
Tujuan penelitian ini adalah menganalisis dan merancang e-commerce pada PT DAF untuk membantu proses penjualan yang kemudian diharapkan dapat meningkatkan pelayanan. Metodologi yang digunakan adalah metode analisis, dimana diadakan peninjauan langsung ke lapangan, mengamati dan menganalisis data yang diperoleh, serta menggunakan metode perancangan, yang mencakup perancangan model bisnis, rancangan layar dan perancangan basis data. Hasil yang ingin dicapai adalah aplikasi e-commerce yang berbasiskan web, di mana sistem ini dapat memudahkan konsumen untuk mendapatkan informasi yang diinginkan secara lengkap, melakukan transaksi lebih mudah dan cepat. Simpulan yang didapat adalah PT DAF dapat memanfaatkan e-commerce sebagai penunjang bisnisnya saat ini dan model bisnis yang sesuai adalah highest-quality model.
\end{abstract}

Kata kunci: web, e-commerce, penjualan, aplikasi, bisnis 


\section{PENDAHULUAN}

Dewasa ini, persaingan dalam dunia bisnis kian kompetitif, untuk itu suatu perusahaan dituntut untuk dapat mengikuti tren agar dapat tetap bersaing dengan perusahaan-perusahaan sejenis lainnya. Ketersediaan informasi yang aktual, produk yang beragam dan berkualitas, dan metode penjualan yang tepat merupakan beberapa faktor penting yang harus dipertimbangkan oleh perusahaan. Untuk dapat memenuhi kebutuhan-kebutuhan tersebut, salah satu teknologi yang sudah ada saat ini dan sangat mendukung adalah teknologi internet.

Pada awalnya internet hanyalah sebuah jendela informasi dalam sebuah jaringan berbasis teks berkecepatan rendah dan digunakan untuk bertukar informasi dari suatu komputer ke komputer lain. Saat ini internet telah mengalami berbagai macam perkembangan teknologi seperti dengan adanya www (world wide web) dan berbagai macam aplikasi grafis dan multimedia yang membuat tampilan internet menjadi interaktif.

Perkembangan internet dewasa ini memberikan kemudahan untuk memperoleh beragam informasi dari berbagai belahan dunia secara cepat, karena pengguna internet dapat mengakses komputer yang memiliki jasa internet kapan saja dan di mana saja sehingga perbedaan waktu dan tempat tidak lagi menjadi masalah. Hal ini menimbulkan ide bagi perusahaan untuk menggunakan internet dalam bentuk website dengan homepage interaktif sebagai pasar global yang dapat digunakan sebagai media untuk melakukan promosi sekaligus memberikan layanan pembelian produk bagi pelanggan yang mempunyai hambatan jarak dan waktu. Sekarang ini banyak perusahaan kecil hingga besar sudah menggunakan teknologi internet sebagai sarana penunjang untuk dapat meraih keuntungan sebesar-besarnya dan menjaga eksistensi perusahaan dalam persaingan dunia bisnis yang semakin kompetitif.

Untuk meningkatkan penjualan serta menjangkau pangsa pasar yang lebih luas, maka akan dibuatkan suatu rancangan e-commerce untuk PT DAF secara online melalui sebuah website, di mana pelanggan dapat melihat dan mendapatkan informasi tentang produk yang ada, serta dapat langsung melakukan transaksi pembelian secara online.

\section{METODE PENELITIAN}

Metode yang digunakan terdiri dari sebagai berikut. Pertama, metode analisis; merupakan metode untuk menganalisis kondisi yang ada di perusahan dan masalah yang dihadapi. Pengumpulan data dilakukan dengan melakukan survei, wawancara dengan beberapa pihak terkait untuk mendapatkan informasi mengenai sistem yang sedang berjalan sebagai dasar untuk perancangan sistem yang akan dibuat serta mencari referensi pustaka. Pada tahap ini, juga digunakan tahap awal dari enam tahap pembangunan e-commerce menurut Rayport dan Jaworski, yakni analisis peluang pasar. Kedua, metode perancangan. Metode perancangan meliputi perancangan model bisnis, antar muka pelanggan (7C framework), komunikasi pasar, implementasi, dan metrics.

\section{Studi Pustaka}

\section{Internet}

Internet adalah sebuah konsorsium dari jaringan-jaringan, yang menghubungkan jutaan komputer dan ribuan jaringan di seluruh dunia (Rayport \& Jaworski, 2003, p30). 


\section{Penjualan}

Menurut Swastha (2001, p8) menjual adalah ilmu dan seni mempengaruhi pribadi yang dilakukan penjual untuk mengajak orang lain agar bersedia membeli barang atau jasa yang ditawarkan. Menurut Mulyadi (1993, p206) bahwa sistem penjualan punya fungsi-fungsi tertentu yaitu fungsi penjualan, fungsi kredit, fungsi gudang, fungsi pengiriman, dan fungsi akuntansi.

\section{E-commerce}

Secara formal e-commerce dapat didefinisikan sebagai berikut : teknologi yang memperantarai pertukaran antara pihak-pihak (secara individu atau organisasi) seperti kegiatan intra atau interorganisasi berbasis elektronik yang memfasilitasi pertukaran tersebut (Rayport \& Jaworski, 2003, p4).

Menurut Akbar (2006, p49), e-commerce adalah kegiatan perdagangan yang dilakukan melalui perantara halaman web di internet. Menurut Rayport dan Jaworski (2003, p11), dalam membangun sebuah e-commerce ada 6 tahap yang harus dilalui:

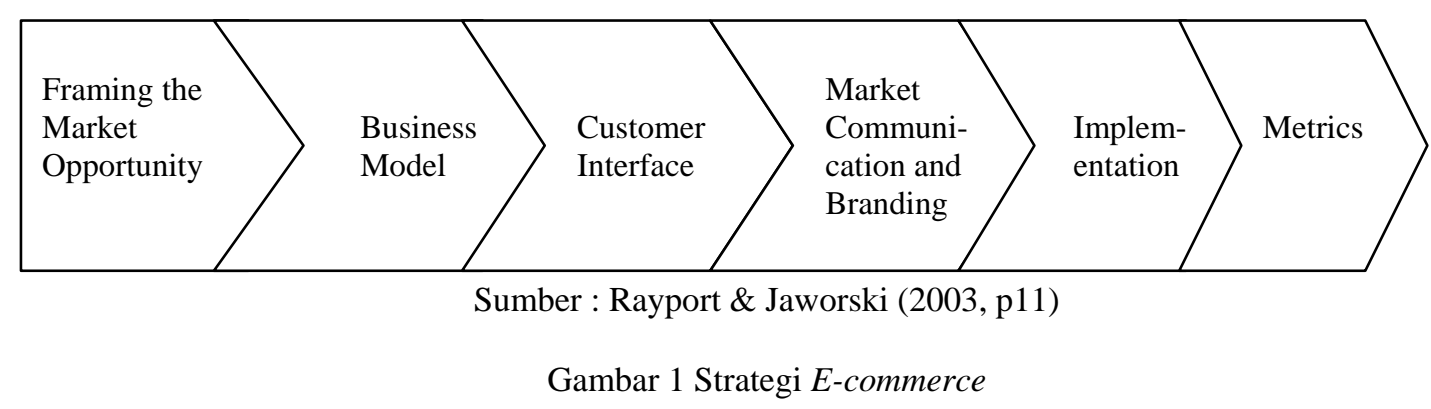

\section{Business-to-Customer e-Commerce}

Menurut Ustadiyanto (2001, p13), B2C (Business-to-Consumer) e-commerce merupakan transaksi jual beli melalui internet antara penjual barang konsumsi dengan konsumen. B2C $e-$ commerce mengacu pada pertukaran antara bisnis dan consumer seperti yang dilakukan oleh Amazon dan Yahoo!, transaksi B2C dapat mencakup pertukaran produk fisik, produk digital, atau jasa dan biasanya lebih kecil daripada transaksi B2B. (Rayport \& Jaworski, 2003, p4)

\section{HASIL DAN PEMBAHASAN}

\section{Tahap Satu: Analisis Peluang Pasar}

\section{Identifikasi Kebutuhan Konsumen yang Belum Terpenuhi}




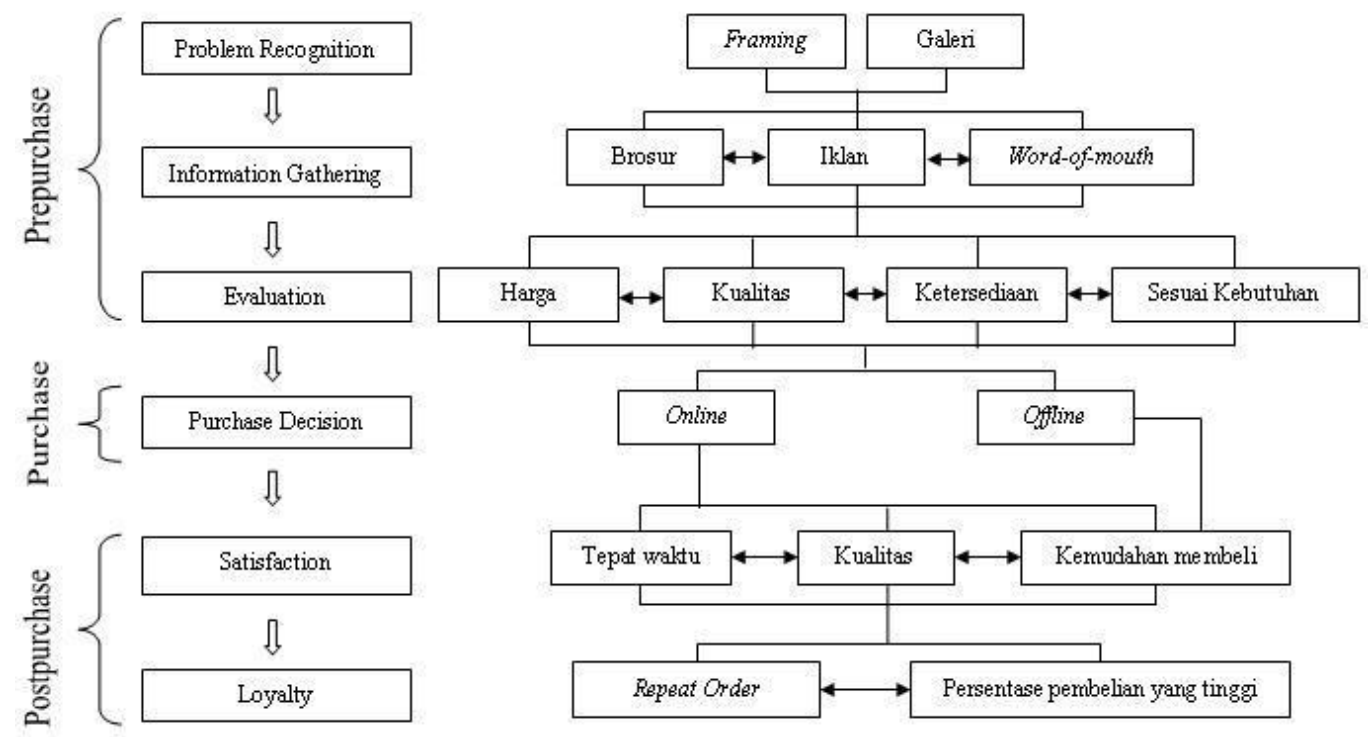

Gambar 2 Consumer Buying Process Tree bagi PT DAF

\section{Identifikasi Target Konsumen}

Dalam menganalisis target segmen, PT DAF mengambil dua parameter untuk menggolongkan pasarnya. Pertama, secara demografi pendapatan, pasar PT DAF dibagi kedalam 3 kelompok yaitu pendapatan tinggi, pendapatan menengah, dan pendapatan rendah. Kedua, secara geografis wilayah (kota) dibagi menjadi Jakarta Selatan, Jakarta Barat, Jakarta Utara, Jakarta Timur, Jakarta Pusat, dan Luar Jakarta.

Tabel 1 Target Segmen Berdasarkan Pendapatan dan Wilayah

\begin{tabular}{|c|c|c|c|c|c|c|}
\hline \multirow[b]{2}{*}{ Pembeli } & \multicolumn{6}{|c|}{ Wilayah } \\
\hline & $\begin{array}{l}\text { Jakarta } \\
\text { Selatan }\end{array}$ & $\begin{array}{c}\text { Jakarta } \\
\text { Barat }\end{array}$ & $\begin{array}{c}\text { Jakarta } \\
\text { Utara }\end{array}$ & $\begin{array}{c}\text { Jakarta } \\
\text { Timur }\end{array}$ & $\begin{array}{c}\text { Jakarta } \\
\text { Pusat }\end{array}$ & $\begin{array}{c}\text { Luar } \\
\text { Jakarta }\end{array}$ \\
\hline $\begin{array}{l}\text { Pendapatan } \\
\text { Tinggi }\end{array}$ & Target utama & & & Target kedua & & \\
\hline $\begin{array}{l}\text { Pendapatan } \\
\text { Menengah }\end{array}$ & \multicolumn{6}{|c|}{ Target ketiga } \\
\hline $\begin{array}{l}\text { Pendapatan } \\
\text { Rendah }\end{array}$ & \multicolumn{6}{|c|}{ Harga Tidak Terjangkau } \\
\hline
\end{tabular}

\section{Menilai Keunggulan Dalam Persaiangan}

JF adalah pesaing langsung dari PT. Dunia Art Frame, sedangkan pesaing lainnya yang juga bergerak dibidang bingkai adalah FF, MAFC, toko-toko bingkai kecil, dan pedagang kaki lima yang secara tidak langsung menjadi pesaing dari PT DAF. 
Tabel 2 Profil Persaingan untuk PT DAF

\begin{tabular}{|c|c|c|c|c|c|}
\hline & $\begin{array}{l}\text { PT. Dunia } \\
\text { Art Frame }\end{array}$ & $\begin{array}{l}\text { Johan } \\
\text { Frame }\end{array}$ & Fuji Film & $\begin{array}{l}\text { Murigo } \\
\text { Art \& } \\
\text { Frame } \\
\text { Collection }\end{array}$ & $\begin{array}{l}\text { Pedagang } \\
\text { kaki lima }\end{array}$ \\
\hline \multicolumn{6}{|l|}{ Customized } \\
\hline \multicolumn{6}{|l|}{$\begin{array}{l}\text { Desain } \\
\text { ukiran } \\
\text { orisinil }\end{array}$} \\
\hline \multicolumn{6}{|l|}{ Fancy frame } \\
\hline \multicolumn{6}{|l|}{$\begin{array}{c}\text { Bahan dasar } \\
\text { kayu }\end{array}$} \\
\hline \multicolumn{6}{|l|}{$\begin{array}{l}\text { Bahan dasar } \\
\text { bukan kayu }\end{array}$} \\
\hline $\begin{array}{c}\text { Teknik } \\
\text { penyambung } \\
\text { frame dengan } \\
\text { mesin }\end{array}$ & & & & & \\
\hline
\end{tabular}

\section{Menilai Sumberdaya Perusahaan dalam Memberikan Penawaran}

Sumber daya customer-facing PT DAF adalah: pertama, ruang pamer. Ini merupakan ruang di mana pelanggan dapat melihat contoh bingkai dan lenen yang ada. Ruang pamer ini hanya terdapat di kantor PT DAF; kedua, brand name. Di kalangan pengguna bingkai, PT DAF cukup memiliki nama karena PT DAF sudah berdiri cukup lama dan memiliki pelanggan tetap yang cukup banyak; ketiga, tenaga penjual. PT DAF juga memiliki orang-orang penjualan yang handal, yang mengerti benar tentang produk PT DAF dan ramah terhadap pelanggan karena perusahaan ini sangat mementingkan kepuasan pelanggan.

Aset internal perusahan yang paling menonjol adalah: bagian produksi yang telah menerima pelatihan dari perusahaan; teknik penyambungan bingkai yang menggunakan mesin sehingga tidak merusak bingkai; serta perancang ukiran-ukiran bingkai yang menghasilkan ukiran-ukiran maha karya yang unik dan tidak boleh ditiru oleh orang lain.

Sumber daya pendukung eksternal dalam PT DAF adalah: pemasok yang menyediakan bingkai-bingkai dengan bahan terbaik yaitu dari kayu berkualitas tinggi yang tidak mudah rusak. Pemasok juga menjaga desain ukiran bingkai yang dimiliki oleh PT DAF agar tidak ditiru oleh perusahaan lain.

\section{Menilai Kesiapan Teknologi yang Dimiliki Pasar}

Pertama, hambatan teknologi. Website sebagai aplikasi e-commerce yang akan diterapkan oleh PT DAF harus dapat diakses dengan layanan low-bandwith, karena akses internet di Indonesia belum mendukung untuk pengoperasian internet secara optimal.

Kedua, teknologi yang berjalan saat ini. Dengan kondisi koneksi internet yang ada di Indonesia, PT DAFe dapat menggunakan koneksi internet seperti DSL (Digital Subscriber Line) atau cable yang kecepatan koneksinya (transfer rate) dan bandwith-nya lebih baik dari dial-up. 
Ketiga, dampak teknologi baru. Penggunaan teknologi baru di masa mendatang diharapkan dapat membuat perusahaan dan pelanggan tetap dapat memaksimalkan fasilitas-fasilitas yang disediakan oleh website PT DAF. Keberadaan video streaming, animasi dan suara pada website di masa mendatang membuat website menjadi lebih menarik.

\section{Peluang-Peluang yang Ditawarkan}

Tabel 3 PT DAF Opportunity Story

\begin{tabular}{|c|c|c|c|c|c|c|c|c|}
\hline & \multicolumn{8}{|c|}{ PT. Dunia Art Opportunity Story } \\
\hline & $\begin{array}{r}\text { Target } \\
\text { Segment }\end{array}$ & $\begin{array}{c}\text { Value } \\
\text { Proporsition }\end{array}$ & $\begin{array}{l}\text { Customer } \\
\text { Benefits }\end{array}$ & $\begin{array}{c}\text { Critical } \\
\text { Resources }\end{array}$ & $\begin{array}{c}\text { Reason to } \\
\text { Believe }\end{array}$ & $\begin{array}{l}\text { Resource } \\
\text { Sourcing } \\
\end{array}$ & $\begin{array}{c}\text { How to } \\
\text { Monetize }\end{array}$ & $\begin{array}{l}\text { Opportunity } \\
\text { Magnitude }\end{array}$ \\
\hline Consumer & $\begin{array}{l}\text {-Galeri } \\
\text { lukisan } \\
\text {-Pelukis } \\
\text {-Hote1 } \\
\text {-Kantor } \\
\text {-Kolektor }\end{array}$ & $\begin{array}{l}\text {-Frame } \\
\text { ekslusif } \\
\text {-Seperangkat } \\
\text { alat khusus } \\
\text { penyambung } \\
\text { frame }\end{array}$ & $\begin{array}{l}\text { - Dapat } \\
\text { melihat } \\
\text { informasi } \\
\text { frame }\end{array}$ & $\begin{array}{l}\text {-Frame } \\
\text { dengan } \\
\text { kualitas kayu } \\
\text { terbaik }\end{array}$ & $\begin{array}{l}\text { - Desain frame } \\
\text { orisinil } \\
\text { - Bahan dasar } \\
\text { berkualitas } \\
\text { - Pengantaran } \\
\text { tepat waktu }\end{array}$ & $\begin{array}{l}\text { - Supplier } \\
\text { frame } \\
\text { batangan }\end{array}$ & $\begin{array}{l}\text { - Target } \\
\text { pasar yang } \\
\text { lebih luas }\end{array}$ & - Low \\
\hline
\end{tabular}

Menilai Peluang yang Dimiliki Perusahaan

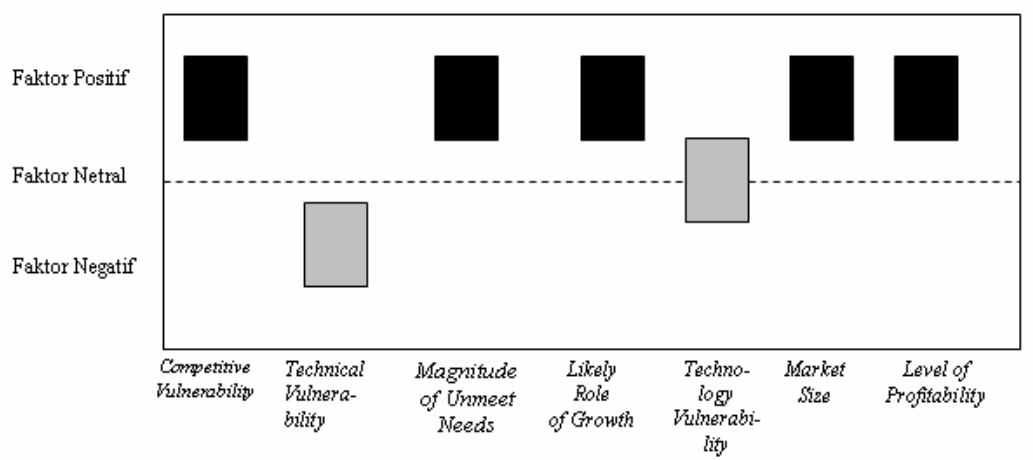

Gambar 3 PT DAF Menilai Peluang

Setelah melakukan analisis 7 faktor di atas, dapat diambil kesimpulan bahwa PT DAF siap untuk menerapkan e-commerce

\section{Tahap dua: Model Bisnis}

\section{Nilai Proporsi}

Pertama, pemilihan segmen. PT Dunia Art Frame memfokuskan target segmen yang ingin dijangkau bagi: galeri lukisan (pendapatan tinggi), kolektor lukisan (penghasilan tinggi), serta pelukis (pendapatan menengah sampai pendapatan tinggi), kantor dan hotel-hotel. Kedua, keuntungan yang ditawarkan adalah kualitas frame yang tinggi, customer service yang handal, jangkauan yang luas dan mudah untuk diakses, serta frame yang bervariasi dan orisinil. Ketiga, sumber daya pendukung, seperti: nama perusahaan yang sudah dikenal, menggunakan mesin pada bagian produksi, serta pemasok yang menyediakan bingkai dengan kayu berkualitas tinggi. 


\section{Penawaran Online}

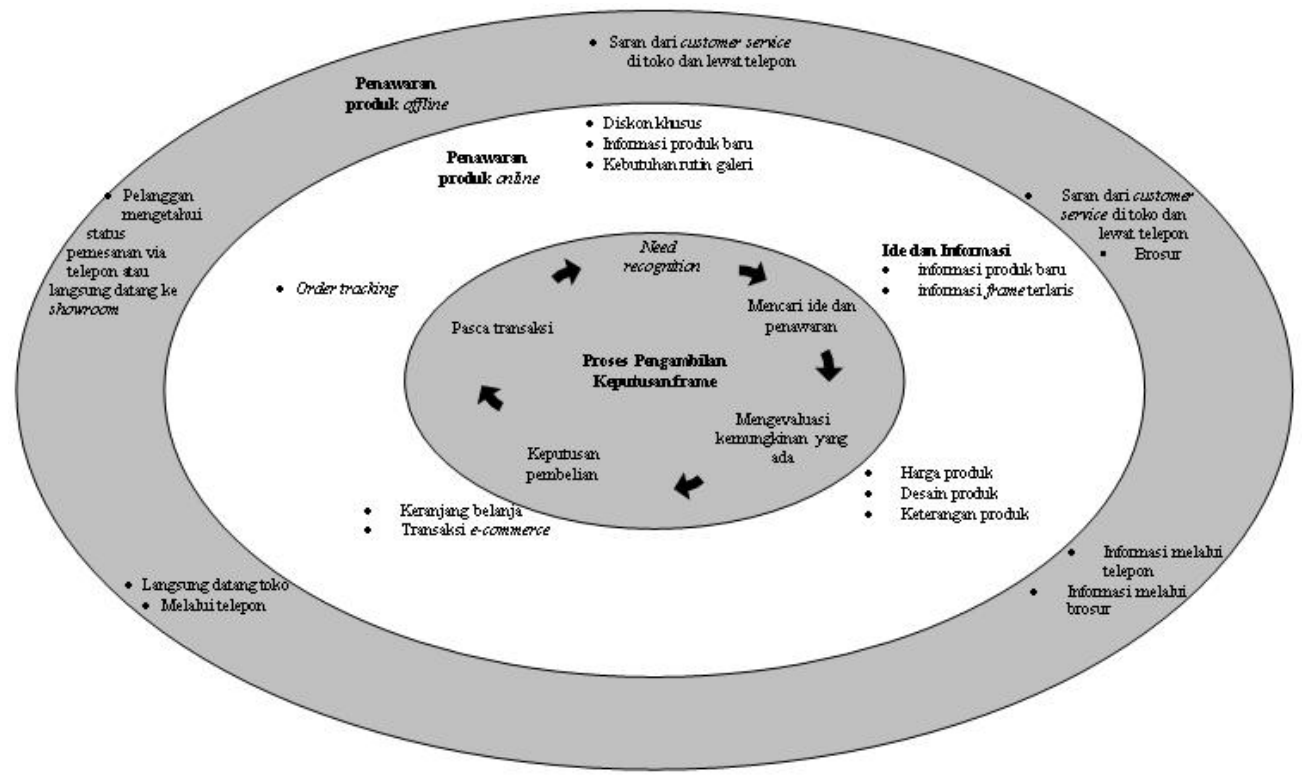

Gambar 4 Online / Offline Egg Diagram PT DAF

\section{Resource System}

Sumber daya sistem menggambarkan bagaimana perusahaan harus memilih dan memadukan sumber daya yang ada untuk menyampaikan keuntungan dari nilai proporsi.

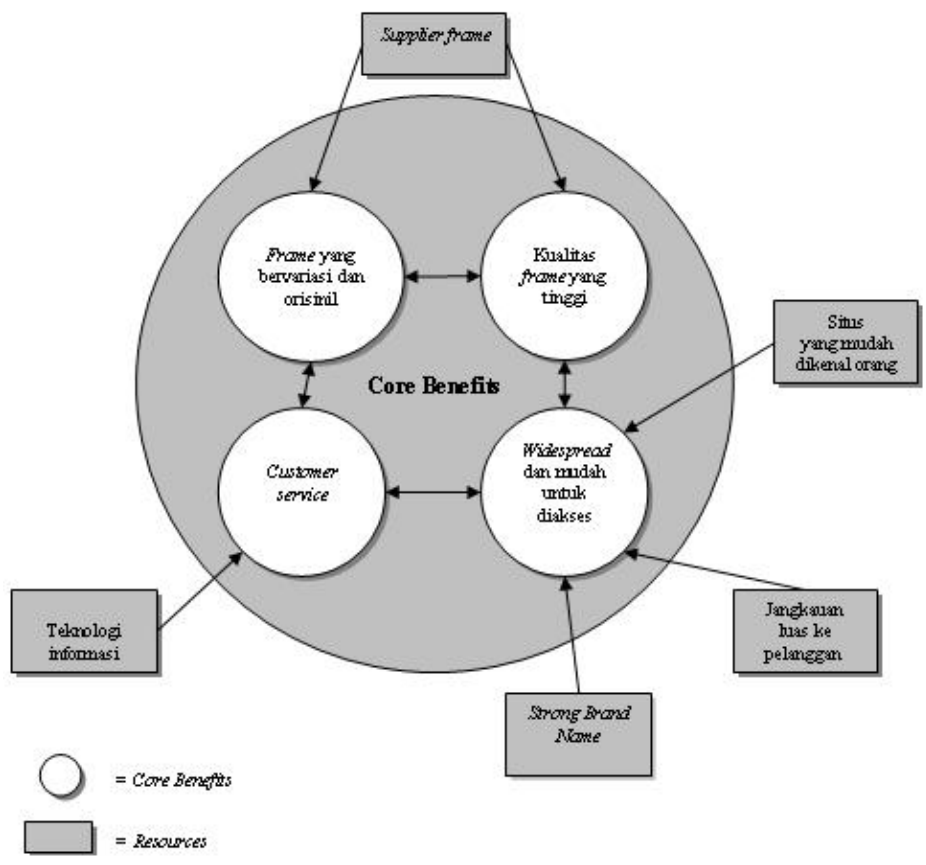

Gambar 5 Sumber Daya Sistem PT DAF 


\section{Model Pendapatan}

Dari analisis terhadap keempat komponen model bisnis di atas, dapat disimpulkan bahwa model bisnis yang diterapkan PT DAF adalah highest-quality model.

\section{Tahap Tiga: 7C Framework}

\section{Context}

Dalam hal context, situs PT DAF berfokus pada dimensi fungsional tanpa mengesampingkan dimensi estetikanya. Elemen-elemen desain dan performa yang terdapat dalam situs PT DAF adalah sebagai berikut. Pertama, section breakdown. Situs PT DAF menempatkan struktur menu pada bagian atas dan kiri bawah situs yang terdiri dari menu data pribadi, Produk, Forum, FAQ, dan Keranjang Belanja bagi member yang sudah login. Namun bagi pengunjung yang belum login, struktur menu yang ada adalah Home, Produk, Forum, Aturan, dan Sejarah. Kedua, linking structure. Link-link yang terdapat dalam situs membuat pengunjung dapat berpindah halaman dengan mudah karena penamaan link disesuaikan dengan fungsi masing-masing link. Misalnya, bila pengunjung hendak melihat atau mengedit data pribadi, pengunjung dapat meng-click menu data pribadi. Ketiga, speed. Situs PT DAF dirancang tanpa menggunakan video atau suara. Image yang digunakan hanya untuk menampilkan produk dan berukuran kecil. komponen flash yang digunakan tidak terlalu besar sehingga situs tidak membutuhkan waktu terlalu lama untuk dibuka di layar pengunjung. Keempat, reliability. Situs PT DAF dapat dibuka dengan tampilan yang sama di layar pengunjung. Namun ketika sistem sedang dalam perawatan, pengunjung hanya dapat masuk ke dalam halaman Home.

\section{Content}

Website PT DAF adalah situs yang bersifat product dominant-category killer di mana situs ini dibangun untuk memberi informasi tentang produk dan menangani transaksi penjualan produk secara online. Didalam content ini, ada empat dimensi yang difokuskan yaitu offering mix, appeal mix, multimedia mix dan timeline mix.

\section{Community}

Komunitas dapat menciptakan membership sense melalui keterlibatan pengunjung dalam sharing informasi. Dalam situs PT DAF disediakan fitur komunitas untuk sharing apapun seputar dunia frame dan lukisan. Fasilitas ini hanya diberikan bagi pelanggan yang telah terdaftar sebagai anggota. Di luar itu pengunjung hanya dapat melihat beberapa topik yang ditampilkan di halaman Forum untuk umum.

\section{Customization}

Dalam situs PT DAF tersedia fitur yang berhubungan dengan customization. Fasilitas yang diberikan hanya tersedia bagi anggota. Situs PT DAF tergolong kategori moderately customized karena fitur-fitur customization yang ada tidak bersifat terlalu customized misalnya dengan adanya fitur mengedit tampilan web sendiri bagi setiap pelanggan.

\section{Communication}

PT DAF menyediakan beberapa alat berkomunikasi. Dari segi broadcast, PT. DA Fmemberikan fasilitas FAQ mengenai produk dan layanan yang ditawarkan. Selain itu, dari segi interactive communication, PT DAF memperbolehkan baik anggota maupun pengunjung dapat memberikan masukan berupa kritik, saran, dan pendapatnya tentang segala fasilitas yang diberikan PT 
DAF. Salah satu fitur komunikasi lain yang ditawarkan PT. Dunia Art Frame adalah dengan adanya status pesanan yang memungkinkan pelanggan untuk melacak status pesanannya.

\section{Connection}

Dalam situs ini tidak disediakan link ke situs lainnya kecuali untuk banner yang akan terpasang, karena PT DAF tidak bekerja sama dengan pihak manapun dalam melakukan proses bisnisnya secara online.

\section{Commerce}

Dalam situs ini terdapat layanan yang berhubungan dengan commerce, tapi fasilitas ini hanya dapat digunakan oleh anggota yang telah terdaftar. Karena tidak semua orang dapat memesan bingkai yang dibuat oleh PT DAF. Pelanggan yang belum terdaftar tetapi ingin melakukan transaksi dapat membuat account terlebih dahulu. Fungsi commerce sendiri dimungkinkan oleh hal-hal, seperti: pendaftaran, shopping cart, security, dan order tracking.

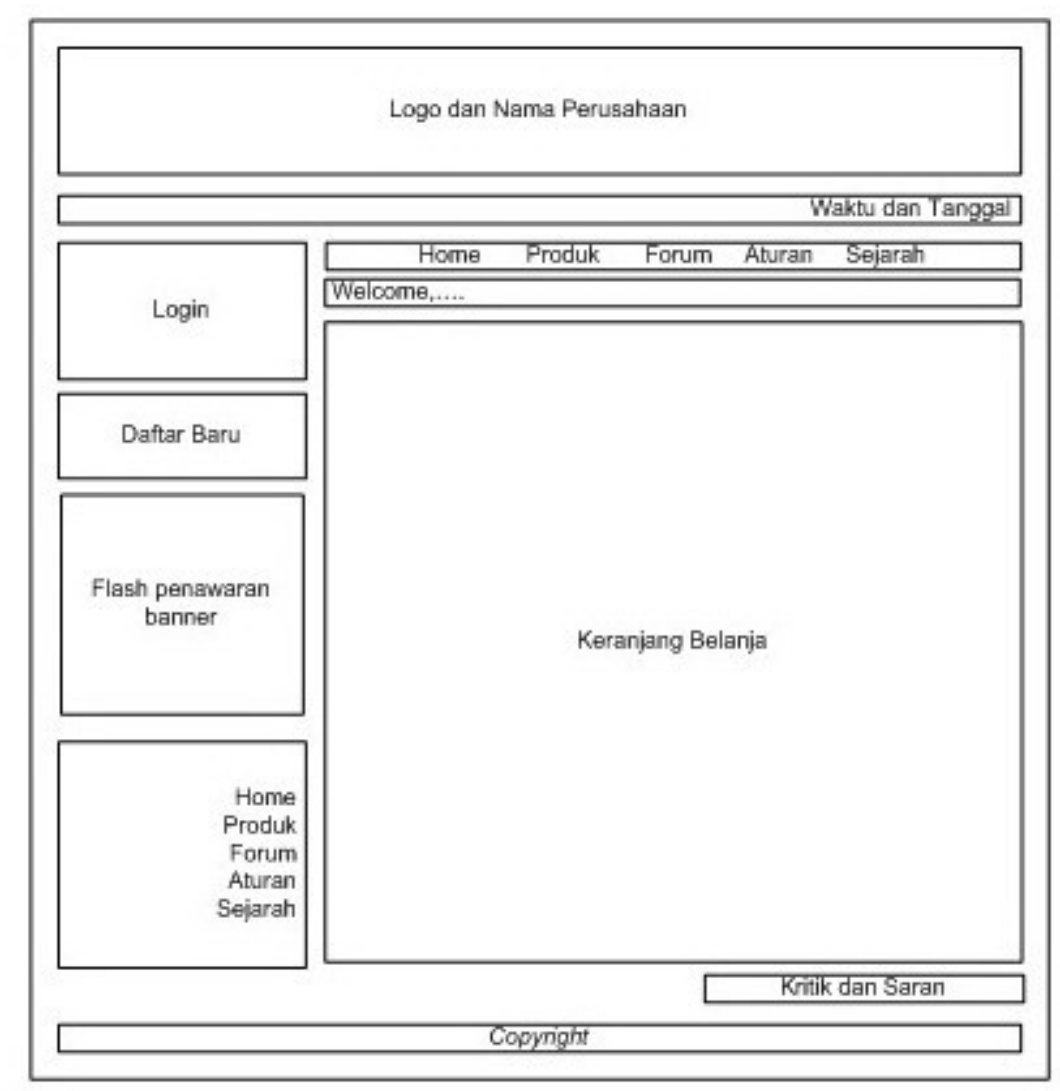

Gambar 6 Halaman Utama

\section{Tahap Empat: Komunikasi Pasar}

Market Communication ditunjukkan lewat gambar 7 yang menggunakan kerangka komunikasi pemasaran untuk mengklasifikasi metode-metode pemasaran dalam empat kategori: general approaches, traditional mass marketing, personalized marketing, dan direct marketing. 
Dalam pendekatan general online approaches, PT DAF menggunakan Online Transaction dan Customer Information. Website PT DAF dapat menangani transaksi secara online. Di mana tujuan utamanya adalah membangun suatu dasar pelanggan yang luas dan hubungan saling percaya dengan pelanggan lewat pembelian frame secara online serta pemrosesan transaksi yang excellent. Selain itu website ini juga menyediakan informasi bagi pelanggan melalui fitur FAQ, customer service melalui e-mail.

Website ini menggunakan media traditional mass marketing untuk memperkenalkan merknya. Media yang digunakan adalah tabloid, brosur-brosur, dan majalah. Metode langsung yang dilakukan oleh PT DAF adalah dengan mendatangi galeri-galeri untuk memperkenalkan produk yang ada dan melalui rekomendasi customer service di toko atau melalui telepon.

Metode pendekatan personalized yang diterapkan berupa personalized recomendation dan personalized e-commerce stores. Ketika pelanggan login ke dalam website, dengan seketika akan ditampilkan produk yang terakhir kali dibelinya berdasarkan behavior pelanggan saat terakhir kali bertransaksi.

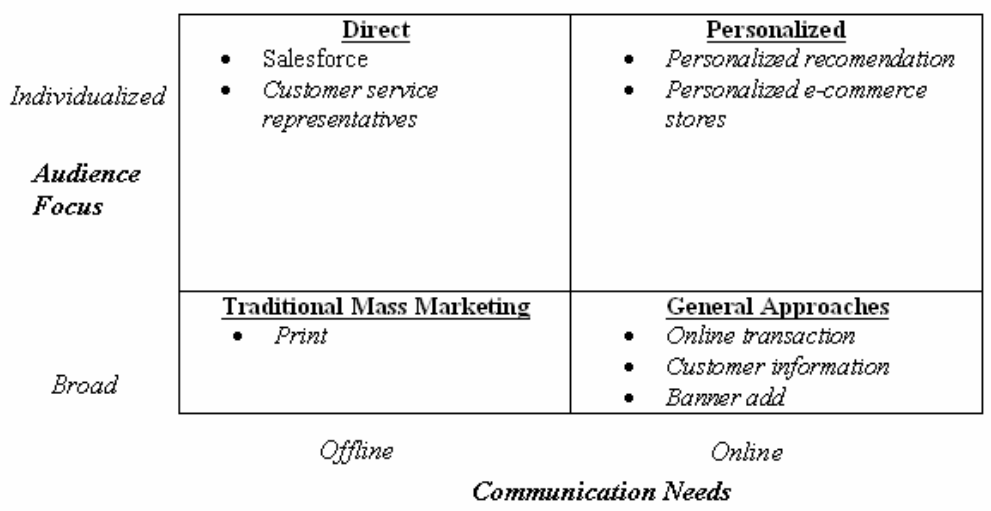

Gambar 7 Komunikasi Pasar PT DAF

\section{Tahap Lima: Implementasi}

Ketika sistem yang dirancang diimplementasikan oleh perusahaan, infrastruktur berupa Sumber daya manusia, Sistem Komputer, dan Kemitraan perlu di perhatikan agar tujuan strategis perusahaan dapat tercapai.

\section{Sumber Daya Manusia}

Dalam mengimplementasikan website ini dibutuhkan sumber daya manusia yaitu karyawan yang khusus bekerja di bagian teknologi, seperti: Manajer IT, programmer, dan admin.

\section{Sistem Komputer}

Berikut ini adalah spesifikasi yang sebaiknya dipenuhi oleh PT Dunia Art Frame. Pertama adalah server, yakni: processor Pentium $42.8 \mathrm{GHz}$, memory 1 GB, dan hard disk 1 GB. Kedua adalah arsitektur jaringan: 


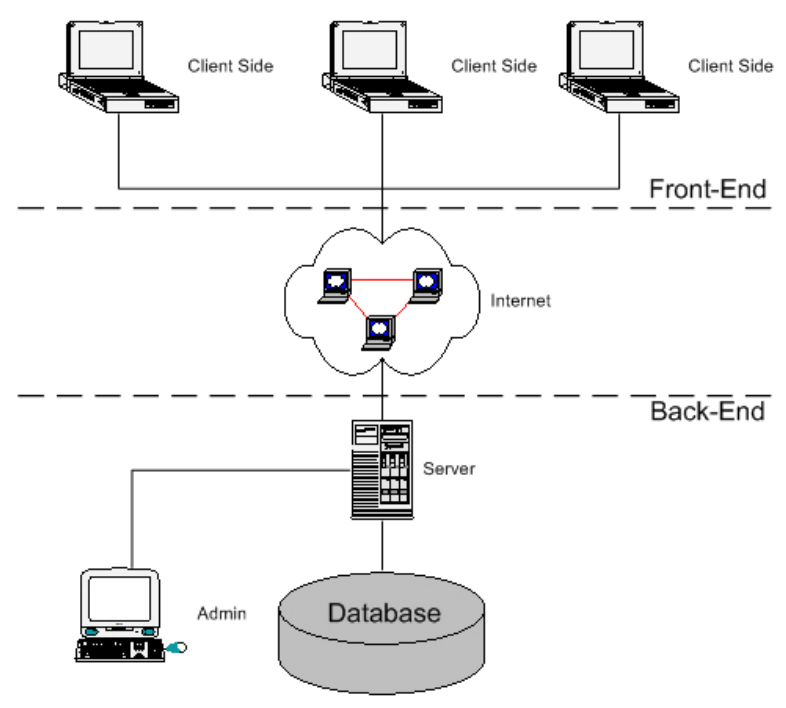

Gambar 8 Arsitektur Jaringan

\section{Kemitraan}

PT DAF perlu bekerjasama dengan perusahaan jasa kurir untuk menangani pengiriman produk ke pelanggan.

\section{Tahap enam: Metrics}

E-commerce yang akan diimplementasikan pada PT Dunia Art Frame nantinya perlu diukur keberhasilannya. Pengukuran ini dilakukan berdasarkan beberapa parameter, seperti: peluang pasar, model bisnis, marketing and branding, implementasi, dan pelanggan.

\section{Tampilan Layar Website PT DAF}

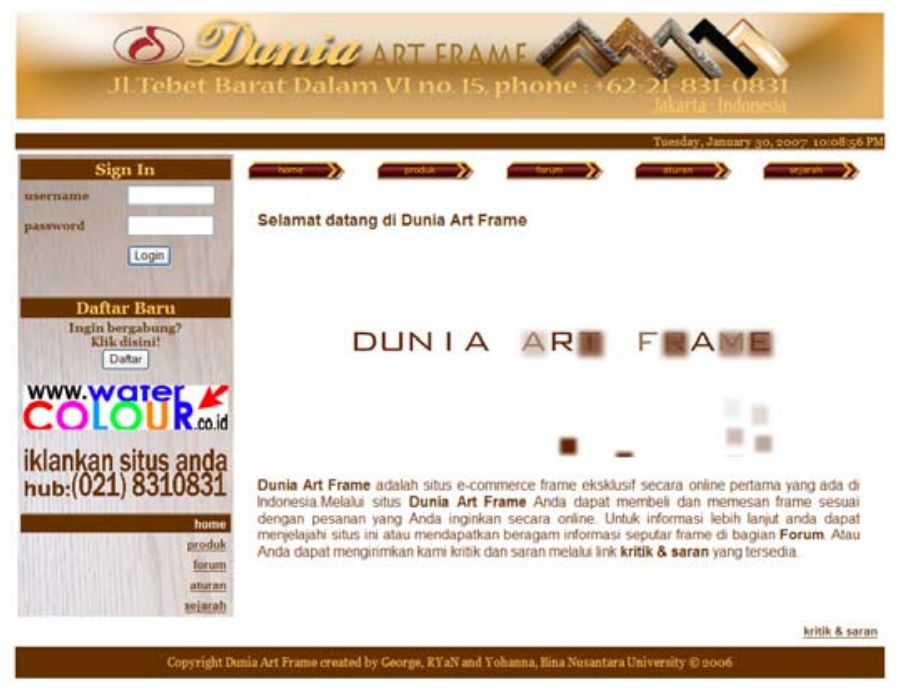

Gambar 9 Halaman Utama pada Situs DAF 


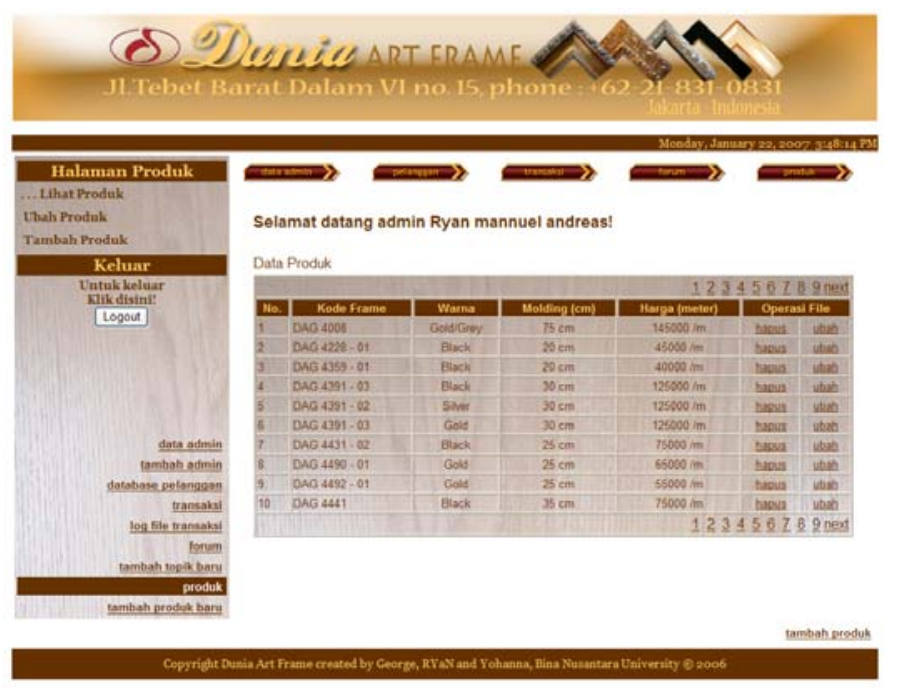

Gambar 10 Halaman Produk Admin pada Situs DAF

\section{SIMPULAN}

Simpulan yang diambil adalah sebagai berikut ini. Pertama, dengan sumberdaya yang dimiliki saat ini disertai dengan peluang-peluang yang akan dihadapai oleh PT DAF, maka PT DAF dapat memanfaatkan e-commerce dalam bisnis yang dilakukannya saat ini. Kedua, dengan adanya aplikasi $e$ commerce ini perusahaan dapat menjangkau target konsumen yang lebih luas, serta dapat membuka peluang calon pelanggan dari luar Jakarta yang tertarik untuk melakukan transaksi dan menggunakan aplikasi ini. Ketiga, model bisnis yang sesuai dengan kondisi perusahaan adalah Highest Quality Model. Keemapat, aplikasi ini juga dibuat untuk memberikan fasilitas kepada konsumen dalam memasarkan lukisan atau properti seni dan dapat langsung berhubungan dengan konsumen lain atau pihak perusahaan secara online melalui forum.

\section{DAFTAR PUSTAKA}

Akbar, A. (2006). Kamus praktis internet untuk semua orang, Semarang: NeoMedia Press.

Chaudury, A., and Piere K. (2002). E-Business and e-commerce infrastructure: technologies supporting the- $e$-Business initiative, New York: Mc Graw Hill.

Connolly, T. M., and Carolyn E. B. (1996). Database systems: a practical approach to design, implementation and management, $3^{\text {rd }}$ ed., Reading, Massachusets: Addision Wesley.

Date, C. J. (1995). An introduction to: database systems, $6^{\text {th }}$ ed., Reading, Massachusets: AddisonWesley.

Ikatan Akuntansi Indonesia. (1991). Standar profesional akuntan, Jakarta: IAI.

Mulyadi. (1993). Sistem akuntansi, edisi ketiga, Yogyakarta: Sekolah Tinggi Ilmu Ekonomi, YKPN. 
Rayport, J. F., and Jaworski, B. J. (2003). Introduction to e-Commerce, $2^{\text {nd }}$ ed., McGraw-Hill Education (Asia).

Smith, J. M., dan Skousen, K. F. (1993). Akutansi intermediate, edisi kesembilan. diterjemahkan oleh Nugroho Widjajanto, Jakarta: Erlangga.

Subekti, M. (1997). Sistem manajemen basis data, Jakarta: Universitas Bina Nusantara.

Swastha, B. (2001). Manajemen penjualan, edisi ketiga, Yogyakarta: BPFE. 